\title{
Acute Metabolic Response to Human Growth Hormone in Different Types of Dwarfism*
}

\author{
K. E. W. MELVIN, M.B., CH.B., B.MED.SC., M.R.C.P., M.R.A.C.P.; A. D. WRIGHT, $†$ M.B., M.R.C.P. \\ M. HARTOG, D.M., M.R.C.P.; A. C. ANTCLIFF, M.B., B.S.; A. M. COPESTAKE, B.SC. \\ T. RUSSELL FRASER, M.D., F.R.C.P.
}

Brit. med. F., 1967, 3, 196-199

The effectiveness of human growth hormone (H.G.H.) in man is now well established from both the acute metabolic response (Beck et al., 1958; Ikkos et al., 1959; Medical Research Council, 1959) and the stimulation of growth after long-term therapy (Raben, 1962). In this paper we report the results of studies of the acute metabolic response to injected H.G.H. in different types of dwarfism and, in some of them, the relation between these responses and the levels of endogenous serum H.G.H. obtained during insulin-tolerance tests. A few of the dwarfed subjects have thereafter received long-term H.G.H. treatment in an attempt to promote growth, and the relation between this growth response and the results of the acute metabolic test has also been examined.

\section{Patients Studied}

Twenty-three patients were studied, and some of their details are shown in the Table. Seven had panhypopituitarism due to a variety of causes and 13 were dwarfed for reasons other than primary pituitary disease; the latter included six "idiopathic" dwarfs, three cases of gonadal dysgenesis, one dwarfed patient with Cushing's syndrome, and three patients on chronic corticosteroid therapy for Still's disease or asthma. The growth response of the patient with Still's disease has been reported separately (Ward et al., 1966). We also report the acute response to H.G.H. in three adults suffering from carcinoma of the breast or osteoporosis, who were presumed to have normal pituitary function. The patients with panhypopituitarism were all receiving replacement therapy with cortisone at the time of the study and four were also receiving thyroxine.

\begin{tabular}{|c|c|c|c|c|c|c|c|}
\hline \multicolumn{8}{|c|}{ Details of Cases } \\
\hline Category & $\begin{array}{l}\text { Case } \\
\text { No. }\end{array}$ & Diagnosis & Sex & Age & $\begin{array}{c}\text { Bone } \\
\text { Age }\end{array}$ & $\begin{array}{l}\text { Height } \\
\text { (cm.) }\end{array}$ & $\begin{array}{l}\text { Weight } \\
\text { (kg.) }\end{array}$ \\
\hline $\begin{array}{l}\text { Yanhypo- } \\
\text { pituitarism }\end{array}$ & $\begin{array}{l}1 \\
2 \\
3 \\
4 \\
5 \\
6 \\
7\end{array}$ & $\begin{array}{l}\text { Craniopharyngioma } \\
\text { \#" } \\
\text { Idiopathic... } \\
\text { o0Y implant } \\
\text { Chromoph. tumour }\end{array}$ & $\begin{array}{l}M \\
M \\
F \\
M \\
F \\
M \\
M\end{array}$ & $\begin{array}{l}15 \\
13 \\
18 \\
17 \\
45 \\
67 \\
45\end{array}$ & $\begin{array}{r}9 \\
8 \\
10 \\
11\end{array}$ & $\begin{array}{l}133 \\
128 \\
150 \\
126\end{array}$ & $\begin{array}{l}41 \cdot 5 \\
28 \cdot 0 \\
44 \cdot 0 \\
26 \cdot 5 \\
81 \cdot 0 \\
84 \cdot 0\end{array}$ \\
\hline $\begin{array}{l}\text { Idiopathic } \\
\text { dwarfs }\end{array}$ & $\begin{array}{r}8 \\
9 \\
9 \\
11 \\
11 \\
12 \\
13\end{array}$ & 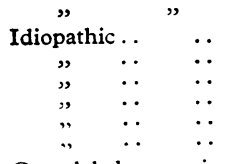 & $\begin{array}{l}M \\
M \\
M \\
M \\
F \\
F \\
F\end{array}$ & \begin{tabular}{r|}
43 \\
9 \\
14 \\
10 \\
16 \\
18 \\
13
\end{tabular} & $\begin{array}{l}6 \\
11 \\
12 \\
16 \\
18 \\
16\end{array}$ & $\begin{array}{l}164 \\
73 \cdot 5 \\
146 \\
141 \\
147 \\
141 \\
143\end{array}$ & $\begin{array}{l}84 \cdot 0 \\
8 \cdot 9 \\
29 \cdot 8 \\
36 \cdot 4 \\
44 \cdot 0 \\
35 \cdot 5 \\
44.0\end{array}$ \\
\hline $\begin{array}{l}\text { Gonadal } \\
\text { dysgenesis }\end{array}$ & $\begin{array}{l}14 \\
15 \\
16\end{array}$ & $\begin{array}{c}\text { Gonadal dysgenesis } \\
\#, " \#\end{array}$ & $\begin{array}{l}(\mathrm{M}) \\
(\mathrm{F}) \\
(\mathrm{F})\end{array}$ & $\begin{array}{l}24 \\
18 \\
16\end{array}$ & $\begin{array}{l}14 \\
16\end{array}$ & $\begin{array}{l}141 \\
132 \\
132\end{array}$ & $\begin{array}{l}39 \cdot 8 \\
42 \cdot 5 \\
30 \cdot 5\end{array}$ \\
\hline $\begin{array}{l}\text { Chronic } \\
\text { cortico- } \\
\text { steroid } \\
\text { excess }\end{array}$ & $\begin{array}{l}17 \\
18 \\
19 \\
20\end{array}$ & 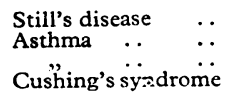 & $\begin{array}{l}F \\
M \\
M \\
M\end{array}$ & $\begin{array}{l}10 \\
16 \\
15 \\
16\end{array}$ & $\begin{array}{c}4 \frac{1}{2} \\
11 \\
11 \\
610 / 12\end{array}$ & $\begin{array}{l}113 \\
146 \\
148 \\
151\end{array}$ & $\begin{array}{l}23.0 \\
43 \cdot 0 \\
58.5 \\
56 \cdot 8\end{array}$ \\
\hline $\begin{array}{l}\text { Miscel- } \\
\text { laneous } \\
\text { adults }\end{array}$ & $\begin{array}{l}21 \\
22 \\
23\end{array}$ & $\begin{array}{l}\text { Carcinoma of breast } \\
\text { Osteoporosis } " ~\end{array}$ & $\underset{\mathrm{F}}{\mathrm{F}}$ & $\begin{array}{l}61 \\
62 \\
62\end{array}$ & & $\begin{array}{l}169 \\
164 \\
164\end{array}$ & $\begin{array}{l}54 \cdot 0 \\
55 \cdot 3 \\
63 \cdot 0\end{array}$ \\
\hline
\end{tabular}

* From the Departments of Medicine and of Chemical Pathology, Royal Postgraduate Medical School of London, London W.12.

This work is part of a trial organized by the Human Pituitary Hormones Subcommittee (chairman: Professor Russell Fraser ; secretary: Dr. A. Stuart Mason) of the Committee of Clinical Endocrinology of the Medical Research Council.

t M.R.C. Junior Research Fellow
The only other patients who were receiving hormonal therapy during the tests were those on corticosteroids. The child with Still's disease (Case 17) was receiving $5 \mathrm{mg}$. of prednisone daily, and the patients with asthma (Cases 18 and 19) were receiving 15 and $12.5 \mathrm{mg}$. of prednisone daily respectively.

\section{Methods}

All patients were studied in the metabolic unit. They were given a standard low-calcium diet containing $68 \mathrm{~g}$. of protein, $68 \mathrm{~g}$. of fat, $220 \mathrm{~g}$. of carbohydrate, $200 \mathrm{mg}$. of calcium, and $1 \mathrm{~g}$. of phosphorus. When necessary this standard diet was altered to meet individual requirements and analysed subsequently. Total calcium intake was standardized to $2 \mathrm{mEq} /$ kg. by means of supplementary calcium tablets. Chromium sesquioxide was given daily $(0.5$ g. t.d.s.) as a faecal marker, and the faecal analyses were corrected according to their content of this marker (Whitby and Lang, 1960). Urine was collected in 24-hour periods and analysed for nitrogen and calcium. Faeces were collected in three-day pools and were analysed for nitrogen, calcium, and chromium. The blood urea was measured daily. A five-day period for equilibration on the diet and chromium was followed by six days of basal measurements ; $10 \mathrm{mg}$. of H.G.H. (Raben, 1962) was then given intramuscularly at 7 a.m. for three days, and the measurements were continued throughout the period of the injections and for the next three days.

Urine and faecal nitrogen were estimated by the Kjeldahl method (Wootton, 1964). Urine and faecal calcium and faecal chromium were measured by means of a flame spectrophotometer (MacIntyre and Brown, unpublished). The blood urea was measured in an autoanalyser. Specimens collected daily were measured in a batch at the conclusion of the study.

Serum H.G.H. was assayed throughout the course of a standard insulin-tolerance test $(0.1 \mathrm{unit} / \mathrm{kg}$.) by an immunoassay method using the double-precipitation technique (Hartog et al., 1964b); the preparation of H.G.H. used as standard was the M.R.C. "A " preparation, and the lower limit of sensitivity of the method was $1-4 \mathrm{~m} \mu \mathrm{g} . / \mathrm{ml}$. The patients receiving corticosteroids and the boy with Cushing's syndrome were given larger doses of insulin $(0.15-0.3 \mathrm{unit} / \mathrm{kg}$.) in view of their expected insulin resistance.

\section{Results}

\section{Acute Metabolic Response to H.G.H.}

Basal measurements were made over the six days before giving H.G.H. From these a mean value was obtained for each of the measurements, against which the subsequent response to H.G.H. was compared. Though the magnitude of the response was greatest during the three days of hormone administration, the duration of action of H.G.H. was greater in the hypopituitary subjects. A better discrimination between different groups of patients was obtained, therefore, by selecting for comparison the six-day period after the first injection of H.G.H. Thus the response was measured in terms of the 
difference between mean basal levels of blood urea, urine nitrogen, and urine calcium, and the mean levels of each during the six days after the first H.G.H. injection (Fig. 1).

In view of the small numbers of subjects in most of the patient categories, the main comparison has been between the hypopituitary subjects and the idiopathic dwarfs.

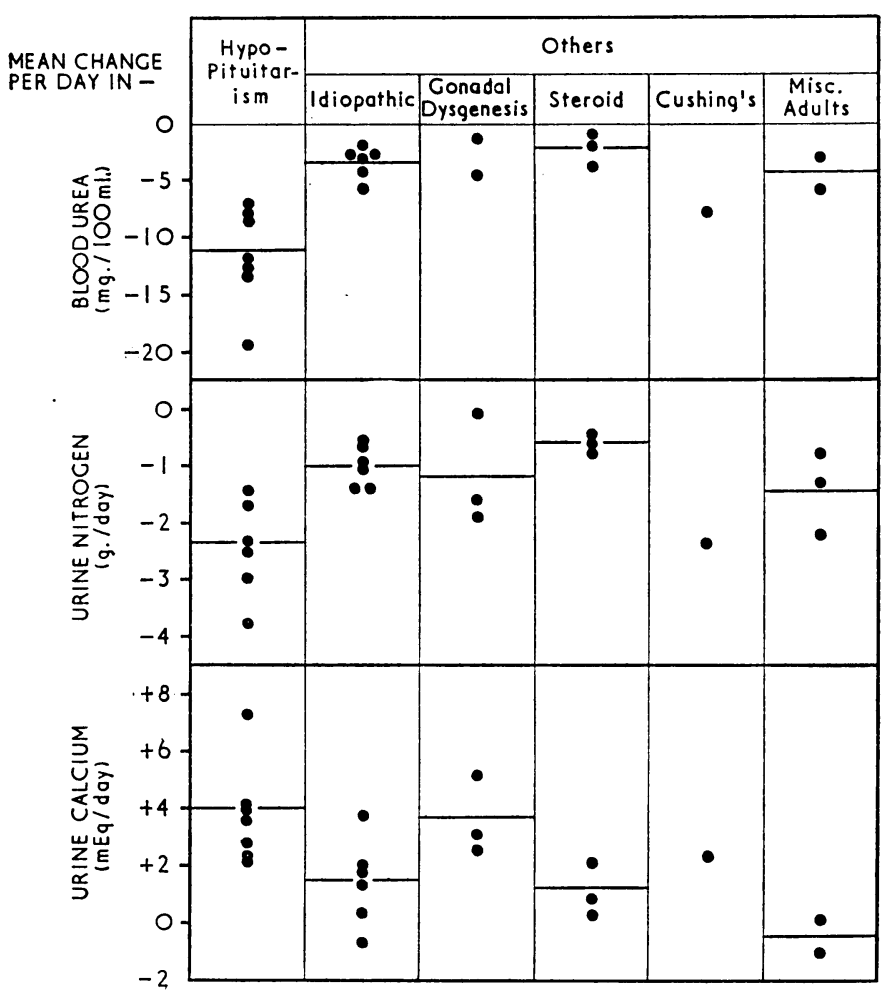

FIG. 1.-Acute metabolic response to H.G.H. (Days 1-6). Mean change per day in blood urea, urine nitrogen, and urine calcium.
(1.0 g./day) $(\mathrm{P}<0.05)$. As shown in Fig. 2, there was a clear correlation between the fall of blood urea in the different subjects and the fall of urinary nitrogen. In Fig. 3 the urine nitrogen response is expressed as a function of body weight. Plotted thus, the distinction between groups of patients is less clear than when plotted in absolute figures.

Nitrogen Balance.-With a single exception, all patients developed a positive nitrogen balance in response to H.G.H. This largely reflected the changes of urinary nitrogen, and little or no change was measured in the relatively small faecal nitrogen values.

Urinary Calcium (Fig. 1).-An increase in the urinary calcium was found in the majority of the subjects. The mean rise was greater in the hypopituitary patients $(3.9 \mathrm{mEq} /$ day) than in the group of idiopathic dwarfs $(1.4 \mathrm{mEq} /$ day $(P<0.05)$, though there was an overlap of individual values in these and the other groups. In particular it was noted that the patients with gonadal dysgenesis showed as large a hypercalciuric effect as did the hypopituitary subjects. A correlation was found between the changes in blood urea and urine calcium (Fig. 4).

Faecal Calcium and Calcium Balance.-No consistent changes were observed in either the faecal calcium or the calcium balance in response to H.G.H.

\section{Relation Between Acute Metabolic Response to H.G.H. and Response of Serum H.G.H. to Hypoglycaemia}

Fourteen of the subjects had measurements of serum H.G.H. performed during an insulin-tolerance test. The highest level of serum H.G.H. found during the test has been plotted against the value of the acute metabolic response to H.G.H., which provided the best discrimination between the different groupsnamely, the fall of blood urea. It will be seen (Fig. 5) that there was some negative correlation $(r=-0.59)$ between these figures. The subjects in whom no measurable rise of serum H.G.H. was found (which included the four hypopituitary

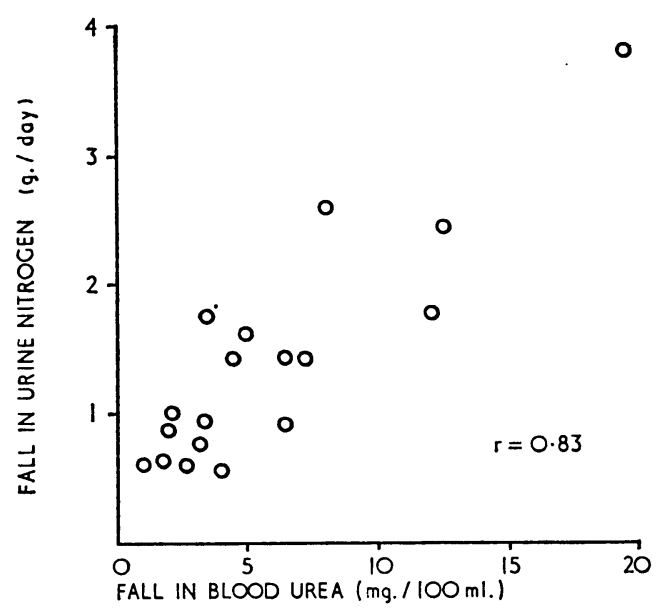

FIG. 2

FIG. 2.- Relation between changes in blood urea and urine nitrogen (Days 1-6).

Blood Urea (Fig. 1).-The fall of blood urea was greater in the patients with hypopituitarism than in the other subjects, with the exception of the boy with Cushing's syndrome. The mean fall in the hypopituitary group $(11.3 \mathrm{mg} . / 100 \mathrm{ml}$.) was greater than that in the group of idiopathic dwarfs $(3.6 \mathrm{mg} . /$ $100 \mathrm{ml}).(\mathrm{P}<0.01)$.

Urinary Nitrogen (Fig. 1).-The patients with hypopituitarism also showe 1 a greater fall of urinary nitrogen than did the other groups of sibjects, though there was some overlap of individual values. The mean fall of $2.4 \mathrm{~g}$./day in the former group was greater than that of the group of idiopathic dwarfs

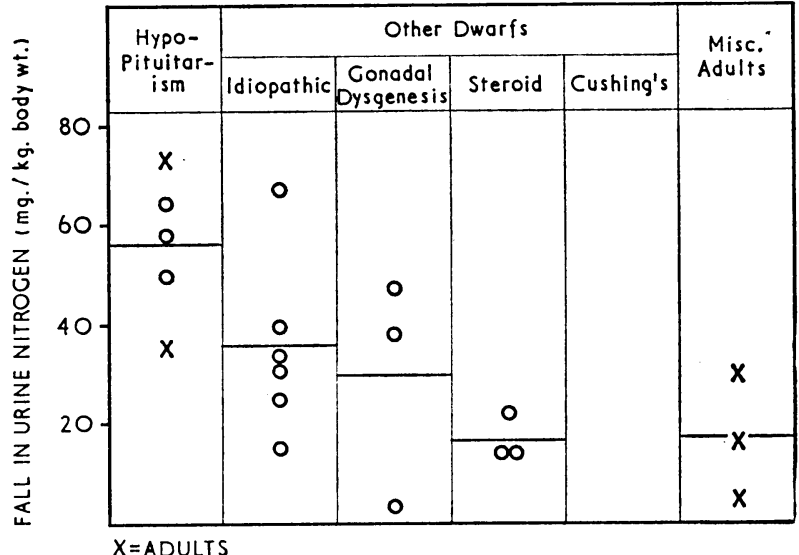

Fig. 3

FIG. 3.-Effect of H.G.H. on urinary nitrogen related to body weight (Days 1-6).

subjects tested and the boy with Cushing's syndrome) sustained a fall of blood urea greater than $7 \mathrm{mg}$. $/ 100 \mathrm{ml}$., while in those in whom clearly measurable rises were found the fall of blood urea was less than $7 \mathrm{mg} . / 100 \mathrm{ml}$.

Relation Between Acute Metabolic Response to H.G.H. and Growth Response to Long-term H.G.H. Treatment

Four patients were studied for periods of at least 12 months on treatment with H.G.H. These comprised the patient with Still's disease (Case 17) and three of the hypopituitary dwarfs 
(Cases 2, 3, and 4). The relation between the fall of blood urea found during the acute metabolic test on these patients and the long-term growth response is shown in Fig. 6 . It will be seen that three of the patients increased their rate of growth by more than $4 \mathrm{~cm}$./year during H.G.H. treatment and that all three had shown a marked fall of blood urea. The fourth rising above $4 \mathrm{~m} \mu \mathrm{g} . / \mathrm{ml}$. during insulin hypoglycaemia were found to sustain only a slight reduction of the blood urea in response to injected H.G.H., whereas the patients in whom serum H.G.H. remained undetectable throughout the insulintolerance test showed greater falls of blood urea. Scott et al. (1966) have reported similar findings. Until more data are

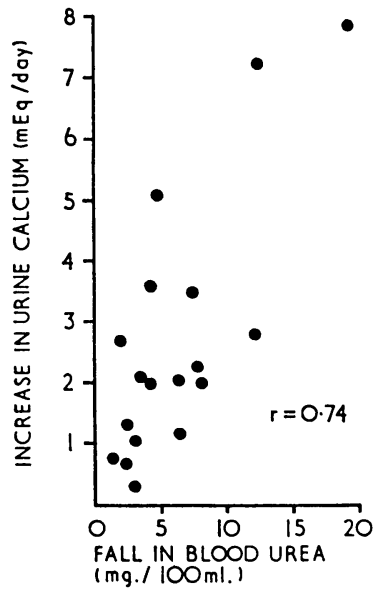

Fig. 4

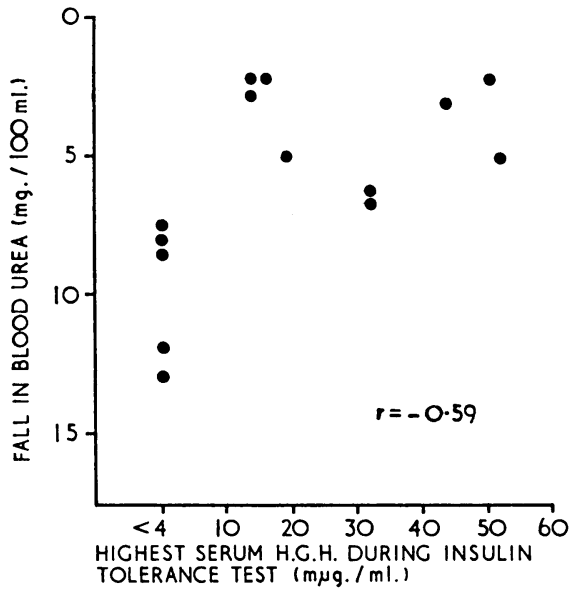

FIG. 5

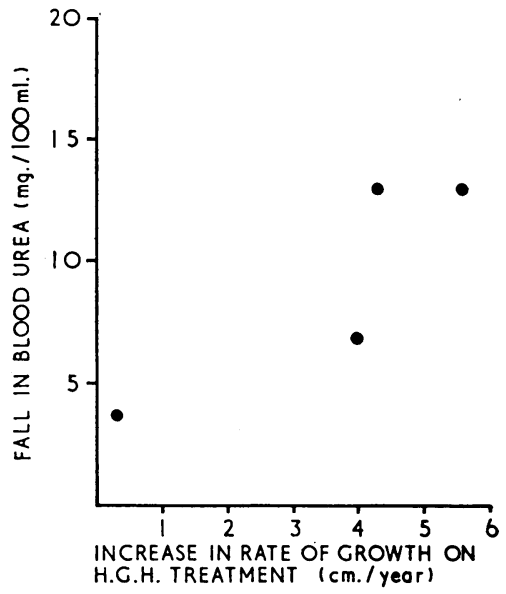

Fig. 6

Fig. 4.-Relation between changes in blood urea and urine calcium (Days 1-6). Fig. 5.-Relation between fall in blood urea (Days 1-6) and highest serum H.G.H. during insulin-tolerance test in 14 patients. FIG. 6.-Relation between fall in blood urea (Days 1-6) and growth response to H.G.H. treatment in four patients.

patient showed no acceleration of growth with chronic H.G.H. therapy and had sustained a fall of only $4 \mathrm{mg} . / 100 \mathrm{ml}$. during the acute metabolic test.

\section{Discussion}

The increased sensitivity of hypopituitary subjects to the metabolic effects of H.G.H. as compared with subjects without hypopituitarism which was found in the present study, agrees with the results of most other investigations (M.R.C., 1959; Daughaday and Parker, 1963 ; Prader et al., 1964 ; Soyka et al., 1964; Wright et al., 1965; Hubble, 1966; Scott et al., 1966). The metabolic response which distinguished our patients with hypopituitarism most clearly from the other subjects was their greater fall of blood urea. Nitrogen retention, as measured by the fall of urinary nitrogen, was also most marked in this hypopituitary group; however, the differences were not as great and the results overlapped more than was found with the blood urea responses, possibly because the autoanalyser blood ureas were more accurate. Even when the changes of urinary nitrogen were corrected for body weight this overlap was still present, though Prader et al. (1964) found a clear separation in this respect between hypopituitary subjects and controls. The hypercalciuric effect of H.G.H. was also more marked in the hypopituitary group, but again there was overlap of individual results with those of the other groups. We did, however, find a correlation between the fall of blood urea and the rise of the urinary calcium induced by H.G.H., which is contrary to the findings of others (Prader et al., 1964 ; Wright et al., 1965) and might not be expected if, as has been suggested, the hypercalciuric effect of H.G.H. is a pharmacological one and related to dosage (M.R.C., 1959).

The usefulness of an acute metabolic trial of H.G.H. in distinguishing patients with hypopituitarism from other forms of dwarfism is supported by the relation between the magnitude of the fall of blood urea and the responsiveness of circulating serum H.G.H. to hypoglycaemia. As fasting levels of serum H.G.H. may be too low to be measured, insulin-tolerance tests were performed to assess H.G.H. reserve, since hypoglycaemia is a well-recognized stimulus for growth hormone release (Roth et al., 1963). Patients with serum H.G.H. levels available concerning the response of normal children to H.G.H., the significance of our results in those patients without primary pituitary disease remains difficult to assess.

Others have also found idiopathic or primordial dwarfs to be resistant to the nitrogen-retaining effect of H.G.H. (Shepard et al., 1960 ; Lipsett et al., 1961), and it seems likely that, though this group of dwarfs is probably a heterogenous one, a peripheral resistance to the action of H.G.H. might be a factor in some.

The cause of the growth defect in gonadal dysgenesis is also uncertain. Normal levels of serum H.G.H. have been found by bioassay (Forbes et al., 1962) and by immunoassay (present study), and Daughaday and Parker (1963) found normal serum sulphation factor in 9 of their 12 patients. A peripheral insensitivity to the action of H.G.H. was postulated by Willemse (1962); however, Forbes et al. (1962) and Wright et al. (1965) measured the metabolic effects of H.G.H. in patients with gonadal dysgenesis and concluded that they were not subnormal. Forbes et al. (1962) suggested that there may be an abnormal form of circulating H.G.H. in this condition. We have tested this suggestion by measuring the serum H.G.H. from two patients by the immunoassay technique at different dilutions of serum. The slope of these assay lines was identical with that of the H.G.H. used in the standards, so that these assays failed to provide any evidence of an abnormal form of circulating H.G.H.

Overdosage with cortisone is a well-known cause of arrested growth, and two mechanisms may be involved in this. A peripheral antagonism between the actions of growth hormone and A.C.T.H. or corticosteroids has been shown both in animals (Becks et al., 1944) and in man (Soyka et al., 1964), and high doses of corticosteroid have been shown to suppress the release of H.G.H. from the pituitary (Hartog et al., 1964a ; Frantz and Rabkin, 1964). It was therefore of interest that the three patients receiving moderate doses of corticosteroids, in whom clearly measurable levels of serum H.G.H. were found, shawed a smaller metabolic response to H.G.H. than that found in the hypopituitary subjects. In contrast, the patient with severe Cushing's syndrome, in whom no circulating H.G.H. could be detected, showed a response similar to that of the hypopituitary group. Hennemann et al. (1964) have also reported 
marked nitrogen retention after the administration of H.G.H. to a patient with Cushing's syndrome.

There are conflicting reports on the usefulness of measuring the metabolic response to H.G.H. in predicting the growth response to long-term H.G.H. therapy. Prader et al. (1964), using a dose of $2 \mathrm{mg}$./sq. m. body surface area daily (Raben preparation), found that four primordial dwarfs sustained only slight nitrogen retention with H.G.H. and failed to respond to long-term therapy, while six out of nine hypopituitary dwarfs who all sustained marked nitrogen retention showed a satisfactory acceleration of growth with long-term H.G.H. therapy. The three exceptions were patients who developed high titres of antibody to H.G.H. in the course of treatment. We have followed the growth response of only four patients, but it did appear that, in them, the degree of nitrogen retention was related to their subsequent course. Wright et al. (1965), using a Wilhelmi preparation $5 \mathrm{mg}$. daily, however, were unable to find any parameter in the metabolic response which was of use in predicting subsequent growth response, with the possible exception of minimal nitrogen retention, which was associated with failure of acceleration of growth with chronic H.G.H. therapy.

\section{Summary}

The acute metabolic response to injected human growth hormone (H.G.H.) has been compared in seven patients with panhypopituitarism, six cases of idiopathic dwarfism, three cases of gonadal dysgenesis, three patients dwarfed as a result of chronic corticosteroid treatment, one case of Cushing's syndrome, and three adults without pituitary disease. Change in blood urea appeared to be the most sensitive factor.

The acute metabolic response was greater in patients with hypopituitarism than in those without primary pituitary disease.

Measurements of endogenous H.G.H. in response to insulin hypoglycaemia were made in 15 subjects. The acute metabolic response to injected H.G.H. was greatest in those with no measurable serum H.G.H. in response to insulin.

The relevance of the acute metabolic response to the linear growth response was examined in four patients who received long-term treatment with H.G.H. Growth was accelerated only in the three patients showing marked nitrogen retention during the acute metabolic test.
Under the Human Pituitary Subcommittee of the Committee of Clinical Endocrinology of the M.R.C. the H.G.H. was prepared by Dr. Anne Hartree, Department of Biochemistry, University of Cambridge, and ampouled, assayed, and tested for sterility and pyrogens by Drs. D. R. Bangham, P. M. Cotes, M. P. StackDunne, and G. W. Bissett, Division of Biological Standards, Medical Research Council. Growth measurements were made by Professor J. M. Tanner and Mr. R. H. Whitehouse at the Institute of Child Health, University of London.

We would like to thank the M.R.C. for a grant for technical assistance for the assay of H.G.H. We also thank the physicians who referred the patients, and the dietitians and nursing and technical staff of the metabolic unit, for all their help in these studies.

\section{REFERENCES}

Beck, J. C., McGarry, E. E., Dyrenfurth, I., and Venning, E. H. (1958). Ann. intern. Med., 49, 1090.

Becks, H., Simpson, M. E., Marx, W., Li, C. H., and Evans, H. M (1944). Endocrinology, 34, 311 .

Daughaday, W. H., and Parker, M. L. (1963). F. clin. Endocr., 23, 638. Forbes, A. P., Jacobsen, J. G., Carroll, E. L., and Pechet, M. M. (1962). Metabolism, 11, 56 .

Frantz, A. G., and Rabkin, M. T. (1964). New Engl. F. Med., 271, 1375

Frantz, A. G., and Rabkin, M. T. (1964). New Engl. J. Med., 271,
Hartog, M., Gaafar, M. A., and Fraser, R. (1964a). Lancet, 2, 376.

- Meisser, B., and Fraser, R. (1964b). Brit. med. F., 2, 1229.

Henneman, P. H., Avioli, L. V., McDonald, J. E., and Melby, T. C. (1964). Proceedings of the Second International Congress of Endo-

crinology, London, p. 1013.
Hubble, D. (1966). Arch. Dis. Childh., 41, 17.

Ikkos, D., Luft, R., and Gemzell, C. A. (1959). Acta endocr. (Kbh.), 32,

Lipsett, M. B., Bergenstal, D. M., and Dhyse, F. G. (1961). F. clin. Endocr., 21, 119.

Medical Research Council (1959). Lancet, 1, 7.

Medical Research Council (1959). Lancet, 1, 7. H. (1964). Arch. Dis. Childh., 39, 535 .'

Raben, M. S. (1962). New Engl. f. Med., 266, 82.

Roth, J., Glick, S. M., Yalow, R. S., and Berson, S. A. (1963). Science, 140, 987

Scott, D. J., Ibbertson, H. K., Farrelly, R. O., Cameron, S., and Harper, P. (1966). N.Z. med. 7., 65, 398 .

Shepard, T. H., Waxman, S., Bernstein, N., and Ferrier, P. (1960). F. Pediat., 57, 363.

Soyka, L. F., Ziskind, A., and Crawford, J. D. (1964). New Engl. J.

Med., 271, 754.
Ward, D. J., Hartog, M., and Ansell, B. M. (1966). Ann. rheum. Dis., 25, 416 .

Whitby, L. G., and Lang, D. (1960). \%. clin. Invest., 39, 854

Willemse, C. H. (1962). Acta endocr. (Kbh.), 39, 204.

Wootton, I. D. P. (1964). Micro-analysis in Medical Biochemistry, 4th ed. London.

Wright, J. C., et al. (1965). Amer. F. Med., 38, 499.

\title{
Chronic Intestinal Ischaemia
}

\author{
J. KENNEDY WATT,* CH.M., B.SC., F.R.C.S., F.R.C.S.GLASG. ; W. C. WATSON, $†$ M.D., PH.D., F.R.C.P.GLASG., M.R.C.P. \\ S. HAASE $\ddagger$ M.A., M.B., CH.B., D.M.R.D.
}

[With Special Plate]

Brit. med. F., 1967, 3, 199-202

When thrombosis of the superior mesenteric artery occurs with acute infarction of bowel the mortality rate approaches $100 \%$ in untreated cases and is over $90 \%$ in those treated surgically (Mavor et al., 1963). The acute episode is preceded by prodromal symptoms of intestinal ischaemia in approximately $50 \%$ of cases (Dunphy, 1936). If these symptoms can be recognized, direct arterial surgery may avert the inevitable arterial occlusion and save life (Morris et al., 1962). The provisional diagnosis of mesenteric ischaemia may be confirmed

\footnotetext{
* Consultant Surgeon, Glasgow Royal Infirmary and Peripheral Vascular Unit, Belvidere Hospital, Glasgow E.1.

† Senior Lecturer in Medicine, Glasgow Royal Infirmary, Glasgow C.4. ₹ Radiologist-in-Charge, Stobhill Hospital, Glasgow N.1.
}

by lateral aortography of the abdominal aorta, but the principal difficulty in diagnosis is a failure to suspect that the presenting symptom pattern may be due to ischaemia of small bowel.

In most cases of chronic intestinal ischaemia due to atherosclerosis at least two of the three principal arteries to the alimentary tract must be stenosed or occluded before symptoms result (Morris et al., 1962), but Morris et al. (1966) reported 6 out of 31 cases in which a lesion of the coeliac axis alone was the cause of symptoms. Marable et al. (1966) reported three cases of stenosis of the coeliac axis caused by constricting bands without superior or inferior mesenteric abnormality. This was the cause of ischaemic foregut symptoms in one of our cases. 